\title{
The Mechanism of Action of Ghlorpromazine
}

\section{REDUCED DIPHOSPHOPYRIDINE NUCLEOTIDE-CYTOCHROME $c$ REDUCTASE AND COUPLED PHOSPHORYLATION*}

\author{
BY M. J. R. DAWKINS, $†$ J. D. JUDAH AND K. R. REES \\ Department of Morbid Anatomy, University College Hospital Medical School, \\ and Department of Biochemistry, University College London
}

(Received 16 October 1958)

In the previous paper (Dawkins, Judah \& Rees, 1959) it was shown that 10-(3-dimethylaminopropyl)-2-chlorophenothiazine (chlorpromazine) was an inhibitor of cytochrome oxidase and also exhibited some action against oxidative phosphorylation. During the course of this investigation, it became apparent that chlorpromazine also had a second point of action in the respiratory chain. This paper describes experiments which indicate the site of action of chlorpromazine. Also included are some observations on the barbiturate 5-ethyl5-isoamylbarbituric acid (Amytal), which has a very similar action (Ernster, 1956). A preliminary communication of these results has been published (Dawkins, Judah \& Rees, 1958).

\section{METHODS}

Animals and enzyme preparations were identical with those described in the previous paper (Dawkins et al. 1959), as were all materials. Mitochondria were subjected to two types of treatment: (1) Pre-incubation in 0.075 M-sucrose for $30 \mathrm{~min}$. at $0^{\circ}$. For this, mitochondria were suspended in $0.25 \mathrm{M}$-sucrose so that the mitochondria derived from $1 \mathrm{~g}$. of liver were contained in $1 \mathrm{ml}$. of suspension. This was diluted with ice-cold water to give a final concentration of $\mathbf{0 . 0 7 5}$ m-sucrose. If required, the mitochondrial concentration was adjusted by dilution with cold $0.075 \mathrm{M}$-sucrose. (2) Pre-incubation in water. The mitochondrial pellets were suspended directly in cold water to make a $10 \%$ suspension and this was diluted with cold water as required. The suspension was held at $0^{\circ}$ for at least $30 \mathrm{~min}$. before use.

The reduction of cytochrome $c$ by $\beta$-hydroxybutyrate and succinate was followed spectrophotometrically, with a Unicam SP. 500 spectrophotometer, by determining the increase in absorption at $550 \mathrm{~m} \mu$. The components of the system were as follows: substrate (sodium salt), $33 \mathrm{~mm}$; cytochrome $c, 40 \mu \mathrm{M}$; inorganic sodium orthophosphate buffer, $\mathrm{pH} \mathrm{7.2,} 33 \mathrm{~mm}$; $\mathrm{NaCN}, 0.1 \mathrm{~mm}$; ethylenediaminetetra-acetic acid (EDTA) neutralized to $\mathrm{pH} \mathrm{7.2}$ with $\mathrm{NaOH}$, mM. Mitochondria were added in a volume of $0 \cdot 1 \mathrm{ml}$. Final volume was $3 \mathrm{ml}$. When reduced diphosphopyridine nucleotide (DPNH) was used as substrate, it was added at a concentration of $0.67 \mathrm{mM}$. Measurements

* Part 1: Dawkins, Judah \& Rees (1959).

$\dagger$ Stothert Research Fellow of the Royal Society. were made at room temperature $\left(20^{\circ}\right)$ in cuvettes with a $1 \mathrm{~cm}$. light path.

In manometric experiments with isolated mitochondria, the following medium was used: adenosine triphosphate (ATP), $1.7 \mathrm{~mm}$; $\mathrm{MgSO}_{4}, 6.7 \mathrm{~mm}$ KCl, $25 \mathrm{~mm}$; glucose, $30 \mathrm{~mm}$; yeast hexokinase, $0.05 \mathrm{ml}$; inorganic sodium orthophosphate buffer, pH 7.2, $10 \mathrm{~mm}$; cytochrome $c$, $20 \mu \mathrm{M}$; substrate, $10 \mathrm{mM}$. Mitochondria were added in $0.5 \mathrm{ml}$. of $0.25 \mathrm{M}$-sucrose, $0.075 \mathrm{M}$-sucrose or water as indicated. Final volume of flask contents was $3 \mathrm{ml}$. The centre well contained $0.1 \mathrm{ml}$. of $30 \%(w / v) \mathrm{KOH}$ and filter paper. The temperature was $38^{\circ}$ and the gas phase was air. Variations from these conditions are noted where relevant.

The exchange reaction between ${ }^{32} \mathrm{P}$ and ATP was studied in the following system: ATP, $2.5 \mathrm{~mm}$; inorganic sodium orthophosphate buffer, $\mathrm{pH} 7 \cdot 2,5 \mathrm{mM}$; $\mathrm{KCl}, 25 \mathrm{~mm}$; $\mathrm{MgSO}_{4}$, $5 \mathrm{~mm}$. ${ }^{32} \mathrm{P}$ equivalent to 15000 counts $/ \mathrm{min}$. was added to each vessel; it was obtained from The Radiochemical Centre, Amersham, Bucks, and purified as described by Kennedy (1953). For the measurement of radioactivity a liquid counter (20th Century Electronics Ltd.; thin-walled B 6) was used. The results were corrected for isotope decay, background and dead time of the instrument. Mitochondria equivalent to $1 \mathrm{mg}$. of $\mathrm{N}$ were added in $0.5 \mathrm{ml}$. of $0.25 \mathrm{M}$-sucrose. The final volume was $2 \mathrm{ml}$. and the tubes were incubated for $15 \mathrm{~min}$. at $20^{\circ}$. 5-Ethyl-5isoamylbarbituric acid (Amytal) was a commercial preparation. ${ }^{82} \mathrm{P}$ incorporated into the nucleotides was measured as described by Nielsen \& Lehninger (1955). All the results quoted in this paper are representative of at least six similar experiments.

\section{RESULTS}

\section{Inhibition of $\beta$-hydroxybutyrate oxidation}

When chlorpromazine at a concentration of $0.2 \mathrm{~mm}$ is present with mitochondria isolated and suspended in $0.25 \mathrm{~m}$-sucrose oxidizing $\beta$-hydroxybutyrate, inhibitions of oxygen uptake are seen (Table 1). At a concentration of $0.1 \mathrm{~mm}$, however, little or no effect may be obtained. Pre-incubation of the particles in $0.075 \mathrm{M}$-sucrose rendered them more susceptible to chlorpromazine, so that $0.1 \mathrm{~mm}$ inhibitor now produced $70 \%$ inhibition of oxygen uptake. This is interpreted as indicating a permeability barrier preventing the access of chlorpromazine to its site of action in the intact particles. 


\section{Table 1. Inhibition of $\beta$-hydroxybutyrate oxidation by chlorpromazine}

The system contained: ATP, $1.7 \mathrm{~mm}$; $\mathrm{MgSO}_{4}, 6.7 \mathrm{~mm}$;Cl, $25 \mathrm{~mm}$; glucose, $30 \mathrm{~mm}$; yeast hexokinase, $0.05 \mathrm{ml}$; inorganic sodium orthophosphate buffer, $\mathrm{pH} \mathrm{7.2,} 10 \mathrm{mM}$; cytochrome $c, 20 \mu \mathrm{M}$; $\beta$-hydroxybutyrate, $10 \mathrm{mM}$. Mitochondria $(0.4 \mathrm{mg}$. of $\mathrm{N}$ ) were added in $0.5 \mathrm{ml}$. of $0.25 \mathrm{M}$-sucrose or $0.5 \mathrm{ml}$. of $0.075 \mathrm{M}$-sucrose. The final volume of flask contents was $3 \mathrm{ml}$. The centre well contained $0.1 \mathrm{ml}$. of $30 \%(\mathrm{w} / \mathrm{v}) \mathrm{KOH}$ and filter paper. Temperature was $38^{\circ}$. Gas phase was air. Readings were commenced after $7 \mathrm{~min}$. thermal equilibration and were continued for 30 min. thereafter. Pre-incubation of mitochondria: mitochondria were held in $0.25 \mathrm{M}$-sucrose or in $0.075 \mathrm{M}$-sucrose for $30 \mathrm{~min}$. at $0^{\circ}$ before addition to the Warburg flasks.

\begin{tabular}{|c|c|c|c|c|}
\hline $\begin{array}{l}\text { Suspension medium } \\
\text { for mitochondria }\end{array}$ & $\begin{array}{l}\text { Concn. of } \\
\text { chlorpromazine } \\
\text { (mM) }\end{array}$ & $\begin{array}{l}\text { Uptake of } \mathrm{O}_{2} \\
\text { with chlorpromazine } \\
(\mu \mathrm{g} . \text { atom of }\end{array}$ & $\begin{array}{l}\text { Uptake of } \mathrm{O}_{2} \\
\text { of control } \\
\text { of } \mathrm{N} / \mathrm{hr} \text {.) }\end{array}$ & $\begin{array}{c}\text { Mean } \\
\text { inhibition } \\
(\%)\end{array}$ \\
\hline $\begin{array}{l}0.25 \mathrm{~m}-\text { Sucrose } \\
0.25 \mathrm{M}-\text { Sucrose } \\
0.075 \mathrm{M}-\text { Sucrose }\end{array}$ & $\begin{array}{l}0.1 \\
0.2 \\
0.1\end{array}$ & $\begin{array}{r}26 \cdot 33 \pm 1 \cdot 25 \\
7 \cdot 83 \pm 1 \cdot 79 \\
9 \cdot 0 \pm 1 \cdot 19\end{array}$ & $\begin{array}{l}26 \cdot 83 \pm 0 \cdot 79 \\
25 \cdot 75 \pm 3 \cdot 04 \\
29 \cdot 66 \pm 1 \cdot 25\end{array}$ & $\begin{array}{r}2 \cdot 5 \\
69 \cdot 5 \\
69 \cdot 8\end{array}$ \\
\hline
\end{tabular}

\section{Table 2. Action of chlorpromazine on phosphorylating and non-phosphorylating mitochondrial systems}

Components of the systems were: ATP, $1.7 \mathrm{~mm} ; \mathrm{KCl}, 25 \mathrm{~mm} ; \mathrm{MgSO}_{4}, 6.7 \mathrm{~mm}$; inorganic sodium orthophosphate buffer, pH 7.2, $5 \mathrm{mM}$; ${ }^{32} \mathrm{P}$ (600 000 counts/min.); cytochrome $c, 66 \mu \mathrm{M} ; \mathrm{NaCN}, \mathrm{mM}$; ethylenediaminetetra-acetic acid, neutralized to $\mathrm{pH} 7 \cdot 2$ with $\mathrm{NaOH}, \mathrm{mM}$; 2-amino-2-hydroxymethylpropane-1:3-diol HCl buffer, pH 7.2, 33 mM; substrate (sodium salt), $33 \mathrm{~mm}$. Mitochondria equivalent to $0.04 \mathrm{mg}$. of $\mathrm{N}$ were added in $0.1 \mathrm{ml}$. of water or $0.075 \mathrm{M}$-sucrose to start the reaction. Final volume was $3 \mathrm{ml}$; temperature $20^{\circ}$. The appropriate blanks did not contain substrate and the results are corrected for blank values as described by Borgstrom, Sudduth \& Lehninger (1955). The reaction was followed for 10 min. by observing the increase in extinction at $550 \mathrm{~m} \mu$ in cells of $1 \mathrm{~cm}$. light path. The esterification of inorganic phosphate was determined by the method of Nielsen \& Lehninger (1955).

\begin{tabular}{|c|c|c|c|c|c|c|}
\hline $\begin{array}{l}\text { Pre-incubation } \\
\text { medium for } \\
\text { mitochondria }\end{array}$ & Substrate & $\begin{array}{l}\text { Concn. of } \\
\text { chlorprom- } \\
\text { azine } \\
\text { (mM) }\end{array}$ & $\begin{array}{c}\text { Cytochrome } c \\
\text { reduced } \\
\text { ( } \mu \mathrm{m}-\mathrm{moles})\end{array}$ & $\underset{\substack{\text { esterified } \\
(\mu \mathrm{m}-\mathrm{moles})}}{\mathrm{P}}$ & $\mathbf{P} / \mathbf{O}$ & $\begin{array}{c}\text { Percentage } \\
\text { inhibition } \\
\text { of electron } \\
\text { transport }\end{array}$ \\
\hline $0.075 \mathrm{M}$-Sucrose & $\beta$-Hydroxybutyrate & Nil & 12 & $7 \cdot 8$ & $1 \cdot 3$ & 一 \\
\hline $0.075 \mathrm{M}$-Sucrose & $\beta$-Hydroxybutyrate & $0 \cdot 1$ & 6 & $4 \cdot 0$ & $\mathbf{1} \cdot 33$ & 50 \\
\hline Water & $\begin{array}{l}\beta \text {-Hydroxybutyrate }+ \\
\text { DPN }(1 \mu \text { mole })\end{array}$ & Nil & 50 & Nil & - & - \\
\hline Water & $\begin{array}{l}\beta \text {-Hydroxybutyrate + } \\
\text { DPN (1 } \mu \text { mole })\end{array}$ & 0.1 & 52 & Nil & 一 & - \\
\hline Water & $\beta$-Hydroxybutyrate & Nil & Nil & Nil & - & - \\
\hline 0.075 M-Sucrose & Succinate & Nil & 53 & $7 \cdot 5$ & $0 \cdot 3$ & - \\
\hline $0.075 \mathrm{M}-$ Sucrose & Succinate & 0.2 & 54 & $8 \cdot 0$ & $\mathbf{0 . 3}$ & Nil \\
\hline Water & Succinate & Nil & 50 & Nil & - & - \\
\hline Water & Succinate & $0 \cdot 2$ & 51 & Nil & - & - \\
\hline
\end{tabular}

There appears to be a species variation in the mitochondrial permeability to chlorpromazine. Mitochondrial preparations from the livers of the Wistar strain of rats used in our Laboratory are apparently more permeable to chlorpromazine than preparations from Norwegian hooded rats.

In the previous investigation (Dawkins et al. 1959) we have shown that the inhibition of $\beta$ hydroxybutyrate oxidation is not relieved by a large excess of cytochrome $c$, and it seemed probable that the inhibition was not due to the effect of chlorpromazine on cytochrome oxidase. We therefore examined the effect of chlorpromazine on the reduction of cytochrome $c$ by $\beta$-hydroxybutyrate. Table 2 shows the results of these experiments.

Mitochondria were pre-incubated in $0.075 \mathrm{M}$ sucrose for $30 \mathrm{~min}$. at $0^{\circ}$ to allow access of the added cytochrome $c$ to the respiratory chain, since particles in $0.25 \mathrm{~m}$-sucrose reduce cytochrome $c$ very slowly under these conditions. It can be seen that chlorpromazine inhibits electron transport when $\beta$-hydroxybutyrate is the substrate, without affecting the efficiency of the coupled phosphorylation. When succinate is the substrate, there is no inhibition whatever. The $\mathrm{P} / \mathrm{O}$ ratio for succinate is low, the theoretical figure for this span being $\mathbf{1} \cdot \mathbf{0}$. However, our results agree with those of Borgstrom, Sudduth \& Lehninger (1955). It will be observed that the phosphorylative efficiency is given as a $\mathrm{P} / \mathrm{O}$ ratio. This is calculated on the assumption that the reduction of cytochrome $c$ is by a one-electron transfer. The ratios are therefore obtained by dividing the $\mu \mathrm{m}$-moles of phosphate esterified by half the $\mu \mathrm{m}$-moles of cytochrome $c$ reduced.

When mitochondria were pre-incubated in water for $30 \mathrm{~min}$. at $0^{\circ}$ the phosphorylation was abolished (see also Lehninger, 1953-54; Judah \& WilliamsAshman, 1951), the rate of reduction of cyto- 
chrome $c$ was accelerated and an absolute requirement for diphosphopyridine nucleotide (DPN) was observed in the system oxidizing $\beta$-hydroxybutyrate. This system was insensitive to chlorpromazine. The succinate system also failed to phosphorylate after pre-incubation in water, and as before was unaffected by chlorpromazine.

In Table 3 are given figures for a somewhat different system, in which cytochrome $c$ is reduced by $\beta$-hydroxybutyrate. In these experiments, the mitochondria were pre-incubated in $0.075 \mathrm{M}$ sucrose or water as before, but the reaction medium did not contain the ATP, hexokinase and glucose or $\mathrm{Mg}^{2+}$ ions which were added for the measurement of oxidative phosphorylation. It can be seen that chlorpromazine inhibits the electron transport in mitochondria pre-incubated in $0.075 \mathrm{M}$-sucrose, but not in those suspended in water.

Similar results were obtained with DPNH as substrate. This substrate was used with mito-

Table 3. Effect of chlorpromazine on the reduction of cytochrome $\mathrm{c}$ by $\beta$-hydroxybutyrate

Components of the system were: $\beta$-hydroxybutyrate, $33 \mathrm{~mm}$; cytochrome $c, 40 \mu \mathrm{M}$; inorganic sodium orthophos-

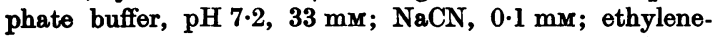
diaminetetra-acetic acid, neutralized to $\mathrm{pH} 7.2$ with $\mathrm{NaOH}$, $\mathrm{mM}$; mitochondria $(0.008 \mathrm{mg}$. of $\mathrm{N})$ were added in $0.1 \mathrm{ml}$. of $0.075 \mathrm{M}$-sucrose or in $0.1 \mathrm{ml}$. of water. With water suspensions, DPN (1 $\mu$ mole) was also added. Final volume was $3 \mathrm{ml}$. Temperature was $20^{\circ}$. The reaction was followed by observing the increase in absorption at $550 \mathrm{~m} \mu$ in optical cells of $1 \mathrm{~cm}$. light path in the Unicam SP. 500 spectrophotometer. Blanks contained all components other than substrate and the reaction was started by addition of enzyme. Readings were taken at $1 \mathrm{~min}$. intervals thereafter for a period of at least $10 \mathrm{~min}$.

\begin{tabular}{|c|c|c|c|}
\hline $\begin{array}{l}\text { Suspension } \\
\text { medium for } \\
\text { mitochondria }\end{array}$ & $\begin{array}{l}\text { Concn. of } \\
\text { chlorprom- } \\
\text { azine } \\
(\mathbf{m M})\end{array}$ & $\begin{array}{c}\text { Cytochrome } c \\
\text { reduçed } \\
\text { ( } \mu \text { moles } / \mathrm{mg} . \\
\text { of } \mathrm{N} / \mathrm{hr} . \text { ) }\end{array}$ & $\begin{array}{c}\text { Inhibition } \\
(\%)\end{array}$ \\
\hline $0.075 \mathrm{~m}-$ Sucrose & - & $12 \cdot 8$ & Nil \\
\hline $0.075 \mathrm{M}-$ Sucrose & $0 \cdot 1$ & $6 \cdot 4$ & 50 \\
\hline Water & - & $15 \cdot 6$ & $\mathrm{Nil}$ \\
\hline Water & $0 \cdot 1$ & $17 \cdot 6$ & Nil \\
\hline
\end{tabular}

chondria in $0.25 \mathrm{M}$-sucrose, mitochondria in $0.075 \mathrm{M}$ sucrose and mitochondria in water. When mitochondria in $0.25 \mathrm{M}$-sucrose are used, the oxidation of DPNH proceeds by the so-called external pathway, which is non-phosphorylating. The same is true of the particles suspended in water, whereas those in 0.075 M-sucrose can utilize the internal phosphorylating pathway (Lehninger, 1953-54). These results indicate that chlorpromazine inhibits the DPNHcytochrome $c$ reductase of the internal mitochondrial pathway, in a manner reminiscent of that of Amytal (Ernster, 1956). The nature of the external DPNH-cytochrome $c$ reductase remains in doubt. One possibility is that microsomal contamination of the mitochondrial preparations is responsible. Distribution studies have shown that most of the total DPNH-cytochrome $c$ reductase activity is present in the microsome fraction (Hogeboom \& Schneider, 1950). If this were the chlorpromazine-insensitive path, it might mean that in water-treated mitochondria electron transport was switched to a non-mitochondrial path. In Table 4 are shown results with mitochondria washed five times in iso-osmotic sucrose by resuspension and sedimentation at $8000 \mathrm{~g}$ for $15 \mathrm{~min}$. for each centrifuging. It may be seen that the DPNHcytochrome $c$ reductase activity of the particles declines considerably. The loss in DPNH-cytochrome $c$ reductase activity is not due to physical loss of mitochondria, since there was only a slight fall $(10 \%)$ in succinoxidase activity during the washing procedure. This decline might be due to leaching of the enzyme from the mitochondria rather than washing out of microsomes. However, the preparation is still sensitive to chlorpromazine and the sensitivity is lost on water treatment. The DPNH-cytochrome $c$ reductase activity of isolated microsomes is not inhibited by chlorpromazine. It seems reasonable therefore to assume that the external pathway for the oxidation of DPNH is a genuine mitochondrial-enzyme system, and not simply due to contamination with microsomes.

It may be observed in Table 4 that, where sucrose suspensions were used, mitochondria were

Table 4. Effect of extensive washing on mitochondrial reduced diphosphopyridine nucleotide-cytochrome c reductase

Components of the system were as described in Table 2, except that DPNH, 0.67 mM, replaced $\beta$-hydroxybutyrate as substrate. Enzyme additions and other methods were also as described in Table 2. The washing procedure for the mitochondria was as described in the text.

Suspension medium for mitochondria 0.25 M-Sucrose Water 0.25 m-Sucrose Water
No. of washes in 0.25 m-sucrose

1
1
5
5

Cytochrome reduced ( $\mu$ moles/mg. of $\mathrm{N} / \mathrm{hr}$.)

$\begin{array}{ccc}\text { Control } & \begin{array}{c}\text { With 0.1 mM- } \\ \text { chlorpromazine }\end{array} & \begin{array}{c}\text { Inhibition } \\ (\%)\end{array} \\ 45 \cdot 0 & 45 \cdot 0 & \text { Nil } \\ 42.5 & 45.0 & \text { Nil } \\ 12.0 & 5 \cdot 0 & 59 \\ 8.8 & 9.6 & \text { Nil }\end{array}$


added in $0.25 \mathrm{M}$-sucrose. The reason for this is that repeated sedimentation and resuspension, even in the presence of mM-EDTA, causes mitochondrial damage and an increase in mitochondrial permeability. This is probably due both to ageing (Christie \& Judah, 1954) and to mechanical disruption. This is inferred from the fact that in parallel experiments when these mitochondria were suspended in $0.075 \mathrm{M}$-sucrose the addition of DPN was necessary before reduction of cytochrome $c$ could be obtained by $\beta$-hydroxybutyrate.

It may be concluded that chlorpromazine inhibits mitochondrial DPNH-cytochrome $c$ reductase. Disruption of the particles removes the inhibition. This release of inhibition might happen in two ways: (1) chlorpromazine acts primarily on a system associated with the electron-transport chain but not part of it, e.g. the oxidative-phosphorylation mechanism. Disruption of the mitochondria in this way would then lead to dissociation of the two systems, and the effect of chlorprom. azine on the respiratory chain would vanish. (2) Chlorpromazine acts on a component of the respiratory chain which is bypassed in disrupted mitochondria. For example, cytochrome $b$ could be the sensitive component of the respiratory chain, since Chance \& Williams (1956) have suggested that it no longer takes part in the non-phosphorylating electron transport which occurs upon waterdisruption of mitochondria.

We investigated these two possibilities of chlorpromazine action. In the section which follows, the effect of chlorpromazine on succinate oxidation is described. Cytochrome $b$ is a com. ponent of this system in both phosphorylating and non-phosphorylating forms (Chance \& Williams, 1956).

\section{Inhibition of succinate oxidation}

In our previous experiments (Dawkins et al. 1959) we had observed that the oxidation of succinate appeared to be relatively insensitive to chlorpromazine. In the system used in these experiments, succinate oxidation does not proceed at the maximal rate and can be considerably increased by increasing the phosphate and cytochrome $c$ concentrations. Under conditions where maximal rates of oxidation are possible chlorpromazine is found to be inhibitory, both in intact mitochondria and in particles disrupted with water, although somewhat less so in the latter (Table 5).

We therefore tested the effect of chlorpromazine on the reduction of cytochrome $c$ by succinate, and have shown (see Table 2) that it was not inhibitory at a concentration of $0.2 \mathrm{~mm}$, whether the mitochondria were suspended in water or $0.075 \mathrm{M}$ sucrose.

It may be concluded that chlorpromazine cannot

\section{Table 5. Inhibition of succinoxidase by chlorpromazine}

Components of the system were: cytochrome $c, 0.4 \mathrm{~mm}$;

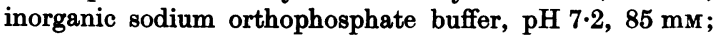
EDTA, mм; succinate, $33 \mathrm{~mm}$. Mitochondria $(0.04 \mathrm{mg}$. of N) were added in $0.5 \mathrm{ml}$. of $0.25 \mathrm{M}$-sucrose or in $0.5 \mathrm{ml}$. of water, as indicated. Final volume in the flasks was $3 \mathrm{ml}$. The centre well contained $0 \cdot 1 \mathrm{ml}$. of $30 \%(\mathrm{w} / \mathrm{v}) \mathrm{KOH}$ and filter paper. Temperature was $38^{\circ}$. Manometric measurements were started after $7 \mathrm{~min}$. thermal equilibration and continued for $60 \mathrm{~min}$. thereafter.

\begin{tabular}{cccc}
$\begin{array}{c}\text { Suspension } \\
\text { medium for }\end{array}$ & $\begin{array}{c}\text { Concn. of } \\
\text { chlorprom- } \\
\text { azine } \\
\text { mitochondria }\end{array}$ & $\begin{array}{c}\text { Uptake } \\
\text { of } \mathrm{O}_{2} \\
(\mu \mathrm{mM})\end{array}$ & $\begin{array}{c}\text { Inhibition } \\
(\%) \text { atoms })\end{array}$ \\
0.25 M-Sucrose & - & $6 \cdot 4$ & Nil \\
Water & $0 \cdot 1$ & $2 \cdot 0$ & 70 \\
& - & $5 \cdot 3$ & $\mathrm{Nil}$ \\
& $0 \cdot 1$ & $2 \cdot 3$ & 54 \\
\hline
\end{tabular}

act on a component common to the DPNHcytochrome $c$ reductase system and the span between succinate and cytochrome $c$. The inhibition of the succinoxidase system by chlorpromazine therefore depends solely on its inhibitory action towards the oxidation of ferrocytochrome $c$ (Dawkins et al. 1959).

In the following sections are described experiments which were designed to test the hypothesis that the action of chlorpromazine is on the coupled phosphorylation mechanism.

\section{Action of chlorpromazine on the ${ }^{32} \mathrm{P}$-adenosine triphosphate-exchange reaction}

We have shown in our previous paper (Dawkins et al. 1959) that chlorpromazine has no effect on the efficiency of the phosphorylation coupled to the reduction of cytochrome $c$ by $\beta$-hydroxybutyrate and L-glutamate, and it was therefore of interest to see whether it would influence the ${ }^{32} \mathrm{P}-\mathrm{ATP}$. exchange reaction described by Boyer, Falcone \& Harrison (1954). These authors ascribed the exchange to a reversal of oxidative phosphorylation, presumably due to electron flux in the steady-state conditions of the mitochondria.

This experiment of necessity has to be conducted in intact mitochondria, since it is known that mitochondrial damage will reduce the exchange (Spector \& Judah, unpublished work).

Table 6 shows that, at $0.2 \mathrm{~mm}$, chlorpromazine brings about a $50 \%$ inhibition of the exchange. Under the conditions of this experiment, adenosine triphosphatase action is negligible, no more than $5 \%$ of ATP phosphorus being set free during the incubation.

This result is of some interest, since it has been shown that antimycin $A$, which inhibits electron 
transport between cytochrome $b$ and $c$ (Chance \& Williams, 1956), has no effect on the exchange reaction (Judah \& Spector, unpublished work).

This effect of chlorpromazine may mean either that the exchange reaction is due largely to electron flux in a limited part of the respiratory chain or that the inhibition by chlorpromazine is due to interference with some factor as yet unknown. This factor may well be related to the oxidative-phosphorylation system, inhibition of which would lead to inhibition of respiration in a phosphorylating system but not in a non-phosphorylating mitochondrial system.

Under these circumstances we felt it would be of interest to see whether 2:4-dinitrophenol can influence the respiratory inhibition caused by chlorpromazine.

\section{Action of chlorpromazine on respiration stimulated by 2:4-dinitrophenol}

The manometric experiments so far cited in this paper were performed in a system designed to give respiratory rates which were not limited by the availability of adenosine diphosphate (ADP) (see Chance \& Williams, 1956). Table 7 shows an experiment in which the effect of chlorpromazine on respiration is shown in a system without added phosphate acceptor. The rate of oxidation of this system is limited by availability of ADP. This system is compared with others in which hexokinase and glucose are added, and one in which dinitrophenol is added. Dinitrophenol under these conditions will stimulate respiration by making the system independent of ADP concentration (Lardy \& Wellman, 1952).

It will be observed that whereas chlorpromazine has little effect on the system which is rate-limited by ADP concentration, it prevents the stimulation of respiration brought about by hexokinase and glucose or by dinitrophenol. This experiment supports the view that chlorpromazine acts upon a phosphorylating process which is closely coupled to the electron-transport chain, and the site of action is at a point before that of dinitrophenol.

Further support for this view is given by the experiments shown in Table 8. In these, chlorpromazine was tested in a system deficient in inorganic phosphate and in which respiration is slow. Contrary to the results obtained with ADP. deficient systems, there was a definite stimulation of respiration. That this was not maximal is shown by the effect of dinitrophenol, which accelerated oxygen uptake about sixfold. In keeping with the hypothesis given above, this extra oxygen uptake was markedly inhibited by chlorpromazine. It may be inferred, also, that the stimulation of respiration by chlorpromazine is due to limited breakdown of some phosphate-containing compound. That it is
Table 6. Effect of chlorpromazine on the ${ }^{32} \mathrm{P}$-adenosine triphosphate-exchange reaction

Components of the system were: ATP, $2.5 \mathrm{~mm}$; inorganic sodium orthophosphate buffer, pH 7.2, $5 \mathrm{mM}$; $\mathrm{KCl}$, $25 \mathrm{~mm} ; \mathrm{MgSO}_{4}, 5 \mathrm{~mm}$. ${ }^{82} \mathrm{P}$ equivalent to 15000 counts/ min. was added to each vessel. For the measurement of radioactivity a liquid counter was used. Measurements were corrected for background counts, isotope decay and dead time of the instrument. Mitochondria (1 mg. of $N$ ) were added in $0.5 \mathrm{ml}$. of $0.25 \mathrm{M}$-sucrose. Final volume was $2 \mathrm{ml}$. and the temperature was $20^{\circ}$. Duration of the experiments was $15 \mathrm{~min}$.

$\begin{array}{lccc} & \begin{array}{c}\text { Incorporation } \\ \text { of }{ }^{32} \text { P into ATP } \\ \text { (counts/min.) }\end{array} & \begin{array}{c}\text { Inhibition } \\ \text { Control }\end{array} \\ \text { Chlorpromazine }\end{array}$

Table 7. Effect of 2:4-dinitrophenol and chlorpromazine on L-glutamate oxidation

Components of the system were as described in Table 1, with the following exceptions: L-glutamate, $10 \mathrm{mM}$, was used as substrate; hexokinase and glucose were omitted unless indicated in the Table; mitochondria equivalent to $1 \mathrm{mg}$. of $\mathrm{N}$ were added in $0.5 \mathrm{ml}$. of $0.25 \mathrm{M}$-sucrose. Final volume was $3 \mathrm{ml}$. Temperature was $38^{\circ}$; the duration of the experiment was $10 \mathrm{~min}$., after $7 \mathrm{~min}$. thermal equilibration.

\begin{tabular}{|c|c|c|}
\hline Additions & $\begin{array}{l}\text { Concn. of } \\
\text { chlorprom- } \\
\text { azine } \\
(\mathrm{mM})\end{array}$ & $\begin{array}{c}\text { Uptake } \\
\text { of } \mathrm{O}_{2} \\
\text { ( } \mu \text { g.atoms) }\end{array}$ \\
\hline Nil & Nil & $4 \cdot 5$ \\
\hline Nil & $0 \cdot 1$ & $4 \cdot 0$ \\
\hline Nil & 0.2 & $\mathbf{3} \cdot \mathbf{6}$ \\
\hline Glucose (30 mM) + hexokinase & Nil & $10 \cdot 0$ \\
\hline Glucose (30 mM) + hexokinase & 0.2 & $4 \cdot 0$ \\
\hline$((33 \mu \mathrm{M})$ & Nil & $8 \cdot 1$ \\
\hline 2:4-Dinitrophenol $\{(33 \mu \mathrm{M})$ & $0 \cdot 1$ & $5 \cdot 0$ \\
\hline (33 $\mu \mathrm{M})$ & $0 \cdot 2$ & $3 \cdot 1$ \\
\hline
\end{tabular}

Table 8. Effect of chlorpromazine on respiration in phosphate-deficient systems

Components of the system were: ATP, $1.7 \mathrm{mM} ; \mathrm{KCl}$, $25 \mathrm{~mm} ; \mathrm{MgSO}_{4}, 6.7 \mathrm{~mm}$; L-glutamate, $10 \mathrm{~mm}$; cytochrome $c$, $20 \mu \mathrm{M}$; inorganic sodium orthophosphate buffer, $\mathrm{pH} 7 \cdot 2$, 1.7 mM; 2-amino-2-hydroxymethylpropane-1:3-diol-HCl buffer, pH 7.2, $33 \mathrm{~mm}$. Mitochondria (0.4 mg. of $\mathrm{N})$ were added in $0.5 \mathrm{ml}$. of $0.25 \mathrm{M}$-sucrose. Final volume was $3 \mathrm{ml}$. There was filter paper in the centre well with $0.1 \mathrm{ml}$. of $30 \%(w / v)$ KOH. Temperature was $38^{\circ}$. Manometric readings were started after $7 \mathrm{~min}$. thermal equilibration and continued for $10 \mathrm{~min}$. thereafter.

\section{Additions}

Uptake of $\mathrm{O}_{2}$

Nil

Chlorpromazine (0.2 mM) ( $\mu$ g.atoms)

2:4-Dinitrophenol (33 $\mu \mathrm{M})$

Chlorpromazine $(0 \cdot 2 \mathrm{~mm})+$

2:4-dinitrophenol (33 $\mu \mathrm{M})$
$1 \cdot 1$

$2 \cdot 1$

6.0 $\mathbf{3 \cdot 6}$ 


\section{Table 9. Effect of Amytal on oxidative phosphorylation with succinate and ferrocytochrome c as substrates}

For the study of phosphorylation coupled to oxidation of ferrocytochrome $c$ the components were as described in Table 1 except that the substrate was L-ascorbic acid (neutralized to $\mathrm{pH} \mathrm{7 \cdot 2}$ with $\mathrm{NaOH}$ just before use), $10 \mathrm{~mm}$. Mitochondria ( $2 \mathrm{mg}$. of $\mathrm{N}$ ) were added in $0.5 \mathrm{ml}$. of $0.075 \mathrm{M}$-sucrose. Final volume was $3 \mathrm{ml}$. The temperature was $20^{\circ}$ and the manometric readings were continued for $60 \mathrm{~min}$. after $7 \mathrm{~min}$. thermal equilibration. For the study of phosphorylation coupled to oxidation of succinate, the components were as described in Table 1 except that sodium succinate, 33 mm, was substrate. Mitochondria $(0.2 \mathrm{mg}$. of $\mathrm{N})$ were added in $0.5 \mathrm{ml}$. of $0.25 \mathrm{M}$-sucrose. Final volume was $3 \mathrm{ml}$. and the temperature was $38^{\circ}$. Thermal equilibration was $7 \mathrm{~min}$. and readings were continued for $30 \mathrm{~min}$. thereafter.

\begin{tabular}{|c|c|c|c|c|c|}
\hline Substrate & $\begin{array}{l}\text { Concn. of } \\
\text { Amytal }\end{array}$ & $\underset{\text { ( } \mu \text { gtatatoms) }}{\text { Uptake } \mathrm{O}_{2}}$ & $\begin{array}{c}\text { Uptake of } P \\
(\mu \text { moles })\end{array}$ & $\mathrm{P} / \mathrm{O}$ & $\begin{array}{c}\text { Inhibition } \\
\text { of } P / O \\
(\%)\end{array}$ \\
\hline Ferrocytochrome $c$ & 一 & $10 \cdot 9$ & $6 \cdot 5$ & $0 \cdot 6$ & Nil \\
\hline Ferrocytochrome $c$ & $2 \mathrm{~mm}$ & $9 \cdot 6$ & $2 \cdot 4$ & $0 \cdot 25$ & 38 \\
\hline Succinate & - & $7 \cdot 3$ & $9 \cdot 7$ & $1 \cdot 33$ & $\mathrm{Nil}$ \\
\hline Succinate & $2 \mathrm{~mm}$ & $6 \cdot 2$ & $5 \cdot 3$ & $0 \cdot 80$ & 40 \\
\hline
\end{tabular}

\section{Table 10. Effect of Amytal on the ${ }^{32} \mathrm{P}$-adenosine} triphosphate-exchange reaction

Components of the system and other details of this experiment were as described in Table 5.

$\begin{array}{lcc} & \begin{array}{c}\text { Incorporation } \\ \text { of }{ }^{32 P} \text { into ATP } \\ \text { (counts/min.) }\end{array} & \begin{array}{c}\text { Inhibition } \\ (\%)\end{array} \\ \text { Control } & 3150 & \text { Nil } \\ \text { Amytal (2 mM) } & 1890 & 60\end{array}$

not due to stimulation of ATP breakdown was shown by analysis of inorganic phosphate before and after incubation, which revealed no change in level of inorganic phosphate in the medium at the end of the experiment.

There was a slight possibility that this stimulation of respiration by chlorpromazine was due to the uncoupling effect, demonstrated previously (see Dawkins et al. 1959). This was excluded by two experiments. In one, the anaerobic reduction of cytochrome $c$ by $\beta$-hydroxybutyrate was studied. Chlorpromazine stimulated this reaction in phosphate-deficient media. In the second, the aerobic oxidation of L-glutamate was stimulated in phosphate-deficient systems by a concentration of chlorpromazine having no uncoupling action $(60 \mu \mathrm{M})$.

\section{Observations on Amytal}

Since our results with chlorpromazine suggest an action similar to that of Amytal described by Ernster (1956), we studied a few properties of the latter. Amytal at a concentration of $2 \mathrm{~mm}$ was shown, in agreement with Ernster, to inhibit glutamate and $\beta$-hydroxybutyrate oxidation by some $\mathbf{8 0} \%$. On succinate oxidation at this concentration it was only slightly inhibitory and we therefore tested its action on oxidative phosphorylation with this substrate and with ferrocytochrome $c$.

Table 9 shows that Amytal inhibits partially the oxidative phosphorylation with both these substrates, and that it does not therefore exhibit any clear-cut separation of effects as does chlorpromazine. Dawkins et al. (1959) have shown that chlorpromazine inhibits the phosphorylation coupled to oxidation of ferrocytochrome $c$ at a concentration which does not affect phosphorylations coupled to the other steps of the electrontransport chain.

Table 10 shows that Amytal at a concentration of $2 \mathrm{~mm}$ inhibits the ${ }^{32} \mathrm{P}-\mathrm{ATP}$ exchange by some $60 \%$, so that in this respect, too, it resembles chlorpromazine.

\section{DISCUSSION}

The evidence presented in this paper shows that chlorpromazine inhibits electron transport between DPNH and cytochrome $c$ in phosphorylating systems. No inhibition is found in non-phosphorylating systems, i.e. in mitochondria disrupted with water. Previously we have shown that even at the inhibited rate in the presence of chlorpromazine the phosphorylating efficiency for this span is normal (Dawkins et al. 1959). Since chlorpromazine does not affect the span succinate to cytochrome $c$ in any system, it follows that none of the components common in both spans is involved. It also follows that chlorpromazine must act between DPNH and flavoprotein.

The observation that chlorpromazine affects only phosphorylating systems suggests the possibility that its action is not directly on the respiratory carriers, but on some intimately coupled system.

We suggest that chlorpromazine acts on some component of the normal phosphorylating mechanisms. The evidence can be summarized as follows:

(1) Chlorpromazine inhibits electron transport between DPNH and cytochrome $c$ without altering the phosphorylating efficiency for the span.

(2) It has little effect on the respiration of DPN. linked substrates which are limited by a low concentration of ADP. 
(3) It prevents the stimulation of respiration in ADP-deficient systems brought about by 2:4dinitrophenol or a phosphate-acceptor system.

(4) It is able to stimulate respiration in a phosphate-deficient system without liberating inorganic phosphate.

(5) It inhibits the ${ }^{32} \mathrm{P}-\mathrm{ATP}$-exchange reaction.

The minimum interpretation of these findings is that chlorpromazine and dinitrophenol act at different points in the sequence of phosphorylation reactions. It would seem that chlorpromazine prevents the formation of the intermediate which is hydrolysed under the influence of dinitrophenol (Chance \& Williams, 1956; Lehninger, 1958). This indicates the existence of at least two intermediates in the series of phosphorylation reactions, which can be formulated into the following sequence:

$$
\begin{gathered}
\mathrm{AH}_{2}+\mathrm{B}+\mathrm{P}_{i} \rightleftharpoons \mathrm{BH}_{2}+\mathbf{A} \sim \mathbf{P} \\
\mathbf{A} \sim \mathbf{P}+\mathbf{X} \rightleftharpoons \mathbf{X} \sim \mathbf{P}+\mathbf{A} \\
\mathbf{X} \sim \mathbf{P}+\mathbf{A D P} \rightleftharpoons \mathrm{ATP}+\mathbf{X}
\end{gathered}
$$

where $A$ and $B$ are respiratory carriers and $X$ is an unknown intermediate. It is postulated that chlorpromazine inhibits reaction (2) and that dinitrophenol hydrolyses the compound $\mathbf{X} \sim \mathbf{P}$.

We believe that this scheme explains our findings by a single hypothesis. Considering the effects of chlorpromazine on electron transport, the scheme shows that in systems respiring freely with an active coupled phosphorylation, reaction (2) becomes rate-limiting in the presence of chlorpromazine. The rate of respiration is reduced, but there is no diminution in the efficiency of the phosphorylation. If inorganic phosphate is lacking, reaction (1) must limit the rate of respiration. In the presence of chlorpromazine, the compound A P would become available for hydrolysis, since reaction (2) is inhibited, and this would permit some stimulation of respiration by chlorpromazine in phosphate-deficient systems. The breakdown of $\mathbf{A} \sim \mathbf{P}$ in the presence of chlorpromazine is necesserily slow, since otherwise chlorpromazine would have an uncoupling action on oxidative phosphorylation without inhibiting respiration. It is clear, also, that when reaction (3) is limiting (ADP-deficient systems) chlorpromazine can have no effect on the respiratory activity of the system.

The scheme also explains why chlorpromazine prevents the stimulatory effect of dinitrophenol on phosphate- and ADP-deficient systems.

Recently, Lehninger (1958) claims to have isolated a phosphate-transferring enzyme catalysing a reaction of the same type as reaction (3). This enzyme is insensitive to dinitrophenol, and Isehninger suggests that it is the terminal step in oxidative phosphorylation. If this is so, then some preceding step must be sensitive to dinitrophenol. From our findings, any formulation which accounts for all the facts must include yet another intermediate.

Lehninger's scheme is as follows:

$$
\begin{aligned}
\mathbf{A H}_{2}+\mathbf{B}+\mathbf{X} \rightleftharpoons \mathbf{A} \sim \mathbf{X}+\mathbf{B H}_{2} \\
\mathbf{A} \sim \mathbf{X}+\mathbf{P}_{\mathbf{i}} \rightleftharpoons \mathbf{X} \sim \mathbf{P}+\mathbf{A} \\
\mathbf{X} \sim \mathbf{P}+\mathbf{A D P} \rightleftharpoons \mathbf{A T P}+\mathbf{X}
\end{aligned}
$$

in which $A$ and $B$ are respiratory carriers and $X$ is an unknown intermediate. $\mathbf{A} \sim \mathbf{X}$ is hydrolysed by dinitrophenol. Clearly, this scheme does not allow for a separate site of action for chlorpromazine. Furthermore, it must mean that dinitrophenol makes the system independent of phosphate concentration, which is not the case. Extensive investigation of this point (Judah, 1951) has shown that the stimulatory effect of dinitrophenol is not observed when the concentration of inorganic phosphate is below a certain critical level. Therefore any intermediate hydrolysed by dinitrophenol must contain inorganic phosphate. In our scheme we have followed the example of Lehninger (1958) in formulating the oxidized respiratory carrier as the 'energy-rich' form, whereas in a previous communication the opposite was inferred from the scheme of Chance \& Williams (1956). This makes little difference to the hypothesis about the site of action of chlorpromazine.

The results with the ${ }^{32} \mathrm{P}$-ATP-exchange reaction support our hypothesis that chlorpromazine inhibits reaction (2). Boyer et al. (1954) suggest that this exchange is due to reversal of oxidative phosphorylation. But Chance \& Williams (1956) point out that there is a possibility that intermediates (e.g. X I in their scheme) could bring ${ }^{32} P$ and ATP into equilibrium. The latter view is supported by our results, since under the conditions of the exchange reaction (i.e. low ADP, high ATP) chlorpromazine has been shown not to inhibit electron flow. In a previous paper (Dawkins et al. 1959) we have shown that the effect of chlorpromazine on oxidative phosphorylation is limited to inhibition of the phosphorylation coupled to the terminal step in electron transport (the oxidation of ferrocytochrome $c$ ). This phosphorylation probably does not play any part in the exchange reaction as neither antimycin A nor cyanide inhibits the exchange reaction. Nevertheless, chlorpromazine inhibits the exchange powerfully. This result is in accord with our interpretation that chlorpromazine interacts with a component of the phosphorylating mechanism coupled to electron flow. It would seem from these results that the major part of the exchange reaction is related to the steps between DPNH and cytochrome $c$. 
The results obtained by Ernster (1956) with Amytal show that its action is very similar to that of chlorpromazine in that it inhibits mitochondrial DPNH-cytochrome $c$ reductase only in undamaged mitochondria. After the mitochondria are damaged with $\mathrm{Ca}^{2+}$ ions Amytal is no longer inhibitory. Our own observations with Amytal show that it also inhibits the exchange reaction but it differs from chlorpromazine in that it uncouples both phosphorylations associated with the oxidation of succinate.

The results of the previous paper (Dawkins et al. 1959) indicate that chlorpromazine uncouples the phosphorylation coupled to the oxidation of ferrocytochrome $c$ and also inhibits cytochrome oxidase. However, a unified hypothesis for all these actions is not possible, since closely related phenothiazines have no action on cytochrome oxidase but are as effective as chlorpromazine on electron transport between DPNH and cytochrome $c$ in a phosphorylating system. Finally, the pharmacological activity must be considered. In the previous paper (Dawkins et al. 1959) we suggested that the inhibitory effect of chlorpromazine on cytochrome oxidase might account for its pharmacological activity. We are investigating a series of compounds related to chlorpromazine. At least one of these has little effect on cytochrome oxidase, but is a powerful inhibitor of DPNH-cytochrome $c$ reductase in phosphorylating systems. This substance is also a powerful tranquillizer and it seems possible that the inhibition of DPNH-cytochrome $c$ reductase is related to tranquillizing activity. It is of interest that the sulphoxide of chlorpromazine has very little activity in our systems. This compound is the detoxication product of chlorpromazine and has no tranquillizing action.

\section{SUMMARY}

1. The action of chlorpromazine on the respiratory chain has been investigated. Inhibition of electron transport between reduced diphosphopyridine nucleotide and cytochrome $c$ has been demonstrated.
2. This inhibition occurs only in phosphorylating systems and is not observed in succinate-cytochrome $c$ reductase systems.

3. The inhibitory action is due to an effect on the coupled phosphorylation reaction rather than that of an interruption in electron transport.

4. Chlorpromazine acts at a point in the phosphorylation reaction other than that affected by 2:4-dinitrophenol.

5. On the basis of these findings a scheme for the reaction involved in oxidative phosphorylation is proposed.

We should like to thank Sir Roy Cameron, F.R.S., for his constant encouragement in this work. We are also indebted to the Graham Research Fund of the University of London, and one of us (J.D.J.) to the Medical Research Council, for funds which have permitted us to carry out this investigation.

\section{REFERENCES}

Borgstrom, B., Sudduth, H. C. \& Lehninger, A. L. (1955). J. biol. Chem. 215, 571.

Boyer, P. D., Falcone, A. B. \& Harrison, W. H. (1954). Nature, Lond., 174, 401.

Chance, B. \& Williams, G. R. (1956). Advanc. Enzymol. 17, 65.

Christie, G. S. \& Judah, J. D. (1954). Proc. Roy. Soc. B, 142, 241.

Dawkins, M. J. R., Judah, J. D. \& Rees, K. R. (1958). Nature, Lond., $182,875$.

Dawkins, M. J. R., Judah, J. D. \& Rees, K. R. (1959). Biochem. J. 72, 204.

Ernster, L. (1956). Exp. Cell Res. 10, 721.

Hogeboom, G. H. \& Schneider, W. C. (1950). J. nat. Cancer Inst. 10, 983.

Judah, J. D. (1951). Biochem. J. 49, 271.

Judah, J. D. \& Williams-Ashman, H. G. (1951). Biochem. J. 48, 33.

Kennedy, E. P. (1953). J. biol. Chem. 201, 399.

Lardy, H. A. \& Wellman, H. (1952). J. biol. Chem. 195, 215.

Lehninger, A. L. (1953-54). Harvey Lect. 49, 176.

Lehninger, A. L. (1958). Science, 128, 450.

Nielsen, S. O. \& Lehninger, A. L. (1955). J. biol. Chem. 215, 555. 